\title{
Time Varying Equilibrium Real Rates and Monetary Policy Analysis*
}

\author{
Bharat Trehan and Tao $\mathrm{Wu}^{\dagger}$ \\ Federal Reserve Bank of San Francisco
}

Revised June 2004

\begin{abstract}
Although it is generally recognized that the equilibrium real interest rate (ERR) varies over time, most recent work on policy analysis has been carried out under the assumption that this rate is constant. We show how this assumption can affect inferences about the conduct of policy in two different areas. First, if the ERR moves in the same direction as the trend growth rate (as is suggested by theory), the probability that an unperceived change in trend growth will lead to a substantial change in inflation is noticeably lower than is suggested by recent analyses (of inflation in the 1970s, for example) that assume a constant ERR. Second, if the monetary authority targets a time varying ERR but the econometrician assumes otherwise, estimated policy rules will tend to exaggerate the degree of interest rate smoothing as well as the weight that the monetary authority places upon inflation.
\end{abstract}

JEL Classification: E52

\footnotetext{
${ }^{*}$ We would like to thank Kevin Lansing and Glenn Rudebusch for helpful comments as well as Mike Atkinson for outstanding research assistance. The views expressed in this paper do not necessarily reflect those of the Federal Reserve Bank of San Francisco or the Federal Reserve System.

$\dagger$ Address for Correspondence: Economic Research, Mail Stop 1130, Federal Reserve Bank of San Francisco, 101 Market St, CA 94105, USA. Email: Bharat.Trehan@sf.frb.org, Tao.Wu@sf.frb.org.
} 


\section{Introduction}

The Taylor rule provides a benchmark for monetary policy in terms of three arguments: the equilibrium real interest rate, the output gap and the inflation rate. Despite its apparent simplicity, it turns out to describe recent monetary policy in the U.S. rather well. It has also been used extensively to analyze the conduct of policy, both in the U.S. and abroad. ${ }^{1}$ However, nearly all the empirical analyses that we are aware of have been carried out under the assumption that the equilibrium real rate (ERR) is constant. One exception is the recent paper by Laubach and Williams (2003), who estimate a model in which the "natural" rate of interest varies over time and show that mismeasurement of this rate can lead to a deterioration in the performance of stabilization policy. In this paper we use their framework (with small modifications) to examine the sensitivity of inferences about monetary policy to assumptions about the ERR.

We show how this assumption matters in two different areas. First, we show how a shifting equilibrium rate can affect inferences about episodes that are sometimes labeled "policy mistakes." In a well known paper, Orphanides (2003, p. 636) states that "The bulk of the error [leading to the 'Great Inflation' of the 1970s] can be traced to the mismeasurement of potential output. Examination of the evolution of estimates of potential output and resulting assessments of the output gap during the 1960s and 1970s suggests that the problem could be attributed in large part to the productivity slowdown which, though clearly seen in the data with the benefit of hindsight, was virtually impossible to ascertain in real time." Lansing (2002a) examines this argument as well. In this paper we show that such arguments are harder to make once one takes into account the fact that the ERR varies over time and, in particular, that it responds positively to changes in the trend growth rate of output. Because of this relationship, slower trend output growth is accompanied by a lower equilibrium interest rate, so that a policy authority which takes a while to recognize that the growth rate of output has slowed down will also take a while to recognize that the equilibrium interest rate has fallen. Thus, policy will, in fact, not be as stimulative as would be suggested by analyses that ignore the link between

\footnotetext{
${ }^{1}$ See, for instance, the volume by Taylor (1999).
} 
trend output growth and the ERR, and inflation will not rise as much.

To illustrate our argument, we present the results from a simulation where, following a reduction in trend output, a monetary authority that bases policy on a Taylor rule with a time varying ERR and filters the data using the correct model of the economy (but does not know about the trend change) generates almost the same amount of inflation as an authority that knows about the trend change. When the exercise is repeated under the usual assumption that the ERR is a constant equal to the observed sample average real interest rate the outcome is a higher inflation rate. Even this increase in inflation is not strikingly large; to get noticeably large increases in the inflation rate, we also have to artificially restrict the speed at which the monetary authority learns about the economy. Our conclusion is that -once time varying ERRs are allowed for- it is not easy to generate significant changes in the inflation rate as the consequence of a mistake about the trend growth rate using Taylor rules and the kind of models used here and in much of the literature. This analysis also applies to the argument recently put forward by Orphanides and Williams (2002), who ignore time variation in the ERR and argue that the fact that inflation did not fall noticeably when productivity accelerated in the 1990s suggests that the Fed may no longer be using rules that depend upon the level of the (unemployment) gap.

Second, we examine what happens to estimates of policy reaction functions in a situation where the monetary authority targets a time varying ERR. If the econometrician ignores time variation in this rate, estimates of two of the three coefficients in a simple policy rule are biased upwards. One of these is the coefficient on the lagged interest rate term; since the size of the lagged interest rate term is generally interpreted as a measure of the extent of interest rate smoothing (see Clarida, Gali and Gertler (1999)) this bias will tend to exaggerate the extent to which the policy authority smooths interest rates. The coefficient on the inflation term is biased upwards as well, and this will make the econometrician overestimate the importance that the authority attaches to controlling inflation. While omitted variable bias accounts for the distortion of the coefficient on the lagged interest rate, the distortion of the inflation coefficient reflects the effects of the monetary authority's filtering the data to recover an estimate of the ERR. This bias affects the coefficient on the output gap as well, but is offset by the fact that the econometrician does not have the 
policymaker's measure of the output gap.

We also discuss two ways of getting around these problems: either by including an ex post measure of the ERR in the estimated reaction function or by allowing for a serially correlated error term, as recommended by English, Nelson and Sack (2003). Either method can eliminate the bias in the interest rate coefficient but neither is completely successful in doing so for the inflation coefficient. Even so, the latter method seems preferable because it requires less information than the former.

\section{The Model}

The equilibrium real interest rate is estimated using a model that is quite similar to Laubach and Williams (2003). The dynamics of the output gap and inflation rate are described by the following backward-looking equations:

$$
\begin{gathered}
\widetilde{y}_{t}=a_{y 1} \widetilde{y}_{t-1}+a_{y 2} \widetilde{y}_{t-2}+\frac{a_{r}}{2} \sum_{i=1}^{2}\left(r_{t-i}-r_{t-i}^{*}\right)+\varepsilon_{1 t} \\
\pi_{t}=\sum_{i=1}^{8} b_{\pi i} \pi_{t-i}+b_{y} \widetilde{y}_{t-1}+b_{x 1} x_{1 t-1}+b_{x 2} x_{2 t-1}+\varepsilon_{2 t}
\end{gathered}
$$

The output gap $\widetilde{y}_{t}$ is defined as

$$
\widetilde{y}_{t}=y_{t}-y_{t}^{*}
$$

where $y_{t}$ and $y_{t}^{*}$ are the logarithms of actual and potential real GDP in quarter $t$, respectively. $\pi_{t}$ denotes the quarterly changes in the core Consumer Price Index (CPI). Inflation is modeled as a very persistent process with $\sum_{i=1}^{8} b_{\pi i}=1^{2} r_{t}$ is the ex-ante real federal funds rate, defined as the difference between the nominal federal funds rate $R_{t}$ and the expected inflation rate of next period:

$$
r_{t}=i_{t}-E_{t} \pi_{t+1}
$$

$r_{t}^{*}$ denotes the equilibrium real interest rate. $x_{1 t}$ and $x_{2 t}$ are two exogeneous variables measuring the inflation rate of imported goods and services relative to changes in the core Personal Consumption Expenditure (PCE) price index and changes in the price

\footnotetext{
${ }^{2}$ For parsimony, we restrict the last four coefficients on lagged inflation to be the same, following Gordon (1998) and Laubach and Williams (2003).
} 
of crude petroleum relative to that of all crude materials included in the Producers' Price Index (PPI), respectively. Thus, the output gap is modeled as a function of its own lagged values and lagged deviations of the real funds rate from the equilibrium real funds rate. Inflation depends upon its own lags and the lagged output gap, as well as oil and import prices.

The unobservable equilibrium real interest rate $r_{t}^{*}$ is assumed to evolve as follows:

$$
\begin{gathered}
r_{t}^{*}=c g_{t}+d f_{t}+z_{t} \\
z_{t}=\sum_{i=1}^{3} \rho_{i} z_{t-i}+\varepsilon_{3 t} \\
y_{t}^{*}=y_{t-1}^{*}+0.25 g_{t} \\
g_{t}=g_{t-1}+\varepsilon_{4 t}
\end{gathered}
$$

where $g_{t}$ is the annualized trend growth rate of real GDP and $f_{t}$ is the ratio of the full-employment fiscal surplus to smoothed total domestic nonfinancial borrowing. ${ }^{3}$ $z_{t}$ represents the remaining influences on the equilibrium real rate, such as the household time preference rate and the population growth rate, which we do not model separately. We assume that $z_{t}$ is a very persistent process, with $\sum_{i=1}^{3} \rho_{i}=1$ in $(4)^{4}$.

Laubach and Williams (2003) also assume an additional random shock to the level of potential output $y_{t}^{*}$, so that $y_{t}^{*}$ is subject not only to changes in the potential growth rate but also to one-time shifts in level. It turns out to be quite difficult to distinguish these one-time shifts in the level from changes in the growth rate, because of which we decided against introducing level shifts. This significantly simplifies the model estimation, as by doing so we avoid the so called "pile-up problem" discussed in Stock (1994).

\footnotetext{
${ }^{3} \mathrm{An}$ alternative is to use potential real GDP to scale the fiscal surplus. However, the debtGDP ratio has increased quite noticeably over our sample period without any obvious disruption in financial markets. Since this may reflect the effects of financial innovation over this period, it seemed to us that government deficits relative to the size of the market would provide a better measure of "crowding out."

${ }^{4}$ The null that the population growth rate process contains a unit root cannot be rejected at the $5 \%$ level in our sample.
} 
As shown in the appendix, the state-space representation of the model becomes

$$
Y_{t}=A^{\prime} X_{t}+H^{\prime} S_{t}+w_{t}
$$

and

$$
S_{t}=F S_{t-1}+v_{t}
$$

where equation (7) is the observation equation and (8) is the state equation of the Kalman filter, and

$$
\begin{aligned}
Y_{t} & =\left(y_{t}, \pi_{t}\right)^{\prime}, \quad S_{t}=\left(y_{t}^{*}, y_{t-1}^{*}, y_{t-2}^{*}, y_{t-3}^{*}, z_{t}, z_{t-1}, z_{t-2}\right)^{\prime} \\
X_{t} & =\left(y_{t-1}, y_{t-2}, i_{t-1}, i_{t-2}, \pi_{t-1}, \pi_{t-2}, \ldots, \pi_{t-9}, x_{1, t-1}, x_{2, t-1}, x_{1, t-2}, x_{2, t-2}, f_{t-1}, f_{t-2}\right)^{\prime}
\end{aligned}
$$

The model is estimated using quarterly U.S. data over the 1965:1 2001:4 period, and the estimates are shown below.

Table A: Parameter Estimates

\begin{tabular}{ccc|ccl|ccc}
\hline \hline$a_{y 1}$ & 1.18 & $(0.08)$ & $c$ & 0.79 & $(0.31)$ & $a_{r}$ & -0.07 & $(0.03)$ \\
$a_{y 1}+a_{y 2}$ & 0.90 & $(0.03)$ & $d$ & -0.10 & $(0.001)$ & $\sigma_{1}(\widetilde{y})$ & 0.78 & $(0.23)$ \\
$b_{\pi 1}$ & 0.02 & $(0.003)$ & $b_{y}$ & 0.28 & $(0.08)$ & $\sigma_{2}(\pi)$ & 1.73 & $(0.35)$ \\
$b_{\pi 2}$ & 0.68 & $(0.09)$ & $b_{x 1}$ & -0.01 & $(0.003)$ & $\sigma_{3}(z)$ & 0.14 & $(0.03)$ \\
$b \pi_{3}$ & 0.30 & $(0.09)$ & $b_{x 2}$ & 0.13 & $(0.02)$ & $\sigma_{4}(g)$ & 0.18 & $(0.05)$ \\
\hline
\end{tabular}

Note: Standard errors are indicated in parentheses.

As can be seen, the coefficients are all statistically significant. Further, the estimated coefficients for the output gap equation (equation 1) are close to the estimates obtained by others for similar models. Laubach and Williams (2003), for instance, obtain a value of 0.94 for $\sum a_{y i}$ and -0.10 for $a_{r}$ while the comparable coefficients in Rudebusch and Svensson (1999) are 0.91 and -0.10. However, our estimate of $b_{y}$ (in equation 2) is about twice as large as that obtained by Rudebusch and Svensson, so inflation is more sensitive to the output gap in our specification. Also, our estimate of $c=0.79$ (in equation 3 ) is a little smaller than the comparable Laubach and William estimate of 1.07, which means that the equilibrium interest rate is not as sensitive to the trend growth rate in our specification as it is in their's. ${ }^{5}$ Finally,

\footnotetext{
${ }^{5}$ Coefficient values from the Laubach-Williams paper are from their baseline case (where $z_{t}$ follows a random walk). See Table 1 in their paper.
} 
note that the sign of $d$ (also in equation 3) is consistent with "crowding out," that is to say a decrease in the fiscal surplus (or an increase in the deficit) leads to an increase in the equilibrium real interest rate.

\section{Policy Analysis}

This section studies the role of the time-varying equilibrium real interest rate in monetary policy analysis. We examine two issues. First, we look at how allowing for a time-varying equilibrium real interest rate affects inferences regarding the conduct of policy when there is a shift in the trend growth of real GDP. Second, we look at what happens to the estimates of a monetary policy reaction function when the econometrician mistakenly assumes a constant equilibrium real interest rate.

We assume that monetary policymakers set rates according to the well known "Taylor rule," in which the level of the nominal interest rate depends on the equilibrium real interest rate, the output gap and inflation. While the precise form of the rule we employ below varies depending on the issues under consideration, the benchmark specification is given by

$$
i_{t}=E_{t} r_{t}^{*}+\hat{\pi}_{t}+\alpha \widetilde{y}_{t}+\beta\left(\hat{\pi}_{t}-\bar{\pi}\right)
$$

where $\hat{\pi}$ denotes the four quarter average of the inflation rate and $\bar{\pi}$ denotes the inflation target of the monetary authority. According to this rule, the monetary authority moves the real rate above its equilibrium value if output is above trend or if the inflation rate is above its target rate. Note that the rule does not contain a lagged value of the nominal interest rate on the right hand side.

\subsection{Changes in the trend growth rate: the 1970s and the 1990s}

The link between trend growth rates and the equilbrium real rate of interest can complicate the task of analysing policy during periods when there is a shift in trend growth rates. Consider, for instance, the argument put forward by Orphanides (1999) and also examined by Lansing (2002a). Orphanides argues that because the Fed did not realize that the trend growth rate had slowed during the 1970s it followed 
a monetary policy that was too stimulative, thereby causing inflation to accelerate. ${ }^{6}$ However, both analyses are based on the assumption of a constant real rate. In this section, we show that such an argument is harder to make if the analysis allows for a time varying interest rate. Essentially, our argument is that if the monetary authority misses the downward shift in the trend growth rate of output it is also going to miss the accompanying decline in the ERR (since the ERR and the trend growth rate are positively correlated from (3) above), and that these two errors will offset each other to some extent. A similar logic applies to some monetary policy analyses of the 1990s. For instance, in their discussion of monetary policy in the 1990s, Orphanides and Williams (2002) argue that if the Fed had been following a Taylor rule during this period it would have engineered a deflation because of a delay in realizing that the trend growth rate had shifted up, and the fact that it did not generate such a disinflation suggests that it was following a more robust rule. ${ }^{7}$ Once again, allowing for a time varying equilibrium real rate makes it harder to justify such a conclusion.

We illustrate these issues by simulating an episode during which the output trend rate changes and show how the subsequent behavior of inflation depends upon the assumed behavior of the ERR. We begin by assuming that the economy is described by equations (1) to (6), so that the equilibrium rate moves over time. Next, we assume that the trend growth rate of output ( $g_{t}$ in (6) above) decreases by 0.15 percent each quarter over a period of 10 quarters, for a total decrease of 1.5 percent. Given the estimate that the coefficient $c$ equals 0.8 in equation (3) above, the drop in $g_{t}$ implies that $r_{t}^{*}$ will fall by 1.2 percent. The economy is also hit by shocks to output, inflation and the ERR, which are assumed to be normally distributed with standard deviations as shown in section 2 above. The inflation target $\bar{\pi}$ is assumed to be 3 percent. We start all simulations at the inflation rate that prevailed at

\footnotetext{
${ }^{6}$ A somewhat different argument is made by Orphanides and Williams (2002), who suggest that the high inflation of the 1970s resulted from misperceived increases in both the natural rate of unemployment and the equilibrium real rate of interest. More specifically, they argue that the ERR rose with the high growth of the 1960s; their estimates of the ERR, however, show a rapid decline in the early 1970s.

${ }^{7}$ Orphanides and Williams (2003) use a policy rule in which the monetary authority reacts to the gap between the unemployment rate and the natural rate instead of the gap between actual and potential output. Their robust rule sets the change in the interest rate as a function of unemployment and inflation gaps.
} 
the end of 1969. Importantly, for our benchmark simulation we assume that agents know the model structure and use the Kalman filter to learn about the shocks to the economy. Such assumptions about rational expectations are quite different from what is assumed in the literature on learning; below, we will discuss what happens when we relax this assumption.

The solid line in panel A of Figure 1 (which is also reproduced in the remaining two panels to facilitate comparison) shows what would happen to inflation if the policymaker were assumed to know the right model and also to know about all the shocks hitting the economy (including the change in trend). Note that in the benchmark case, the inflation rate at the end of the simulation is a little bit lower than it was at the beginning. The associated ERR is shown in Figure 2 with the label "actual real rate." Next we drop the assumption that policymaker knows about the shocks hitting the system and assume, instead that the policymaker uses the (onesided) Kalman filter and the correctly specified model to obtain estimates of these shocks. The inflation rate (shown as a dashed line in panel A of Figure 1) turns out to be quite close to the rate generated under the full information case and is, in fact, slightly lower by the end of the simulation. Essentially, what happens here is that the effects of the initial over-estimate of the reduced trend growth rate are offset by the over-estimate of the equilbrium real interest rate (see Figure 2), so that inflation does not move very far from the full information case. Of course, the almost exact offset between these two cases is not guaranteed, and the exact outcome will depend upon the shocks hitting the system, both historically (since these determine the variances used in the Kalman filter) as well as over the course of the simulation. For instance, a large increase in the ERR (which occurred at about the same time as, but was unrelated to, the decrease in trend growth) could lead to an inflation rate substantially higher than the full-information inflation rate.

Consider next what happens in a simulation where the shocks are the same as before but where the ERR is assumed to be constant. The value of the constant equilibrium rate to be used in the Taylor rule (10) is obtained in a way that is similar to Orphanides (1999) and $\operatorname{Lansing}(2002 \mathrm{a}){ }^{8} \quad$ Specifically, this rate is obtained by

\footnotetext{
${ }^{8}$ Orphanides uses a value of 2 percent for the equilibrium real rate which he points out is the value in Taylor's original specification and is also close to the 2.2 percent "..average ex post interest rate for the estimation sample." (See page 12.)
} 
taking an average of the expost real rate generated in the simulation, and is shown in Figure 2 with the label "ex-post mean." The result of this exercise is an inflation rate (shown as the dashed line in the middle panel of Figure 1) that begins to exceed the inflation generated in the "full information" case soon after the downward shift in the growth rate is complete, and is consistent with the contention that such a downward shift is likely to lead to an increase in inflation.

The assumption about the ERR turns out to be crucial for this result. Taking an average of the ex post real rate during a period in which the actual ERR is high in the early part of the sample but falls later on leads to an estimate that is too low (relative to the actual rate) early on and too high later in the sample. The resulting simulation generates an inflation rate that is higher than what the full-information simulation produces. However, other ways to do a simulation with a fixed ERR can produce inflation outcomes that are quite different. For instance, consider a monetary authority that has been operating in a high trend-output-growth regime for a while and which also believes that the equilibrium interest rate is constant. It is likely that the (constant) ERR estimate of such an authority will reflect the high actual equilibrium rates that prevail during this period, and it is unlikely that this estimate will decline very quickly following an unperceived decline in the trend growth rate. For instance, if the monetary authority were to follow the practice of using the average of the expost real rate over the data sample actually at hand at the time of setting policy as an estimate of the equilibrium rate, a reduction in the trend growth rate (with the resulting decline in the true ERR) could leave its estimate of the ERR above the true ERR for an extended period of time. The size and persistence of this error would, of course, depend upon variables such as the length of the previous high growth regime as well as the size of the shift in the trend growth rate. As an extreme example, we show what would happen to the inflation rate if the monetary authority conducted policy during the low growth period (that is, during a period in which the trend growth rate had fallen) using an estimate of the ERR that was fixed at the value attained at the end of the high growth period (shown as the "High-Growth Real Rate" in Figure 2). In this extreme case, the inflation rate (shown as the dashed line in Panel $\mathrm{C}$ of Figure 1) actually falls below that generated under the full information assumption. By the end of the simulation 
the size of the shortfall is about the same as the size of the increase in inflation in Panel B of the figure.

A noticeable feature of the simulations shown here is that the costs of "policy mistakes" about the trend growth rate appear to be relatively small. Specifically, the difference between the inflation rates generated in either of the two simulations where the ERR is assumed fixed (whether at the sample average or at the beginningof-sample value) and the full information case is around 1 to $1-1 / 2$ percent, even by the end of the simulation. By comparison, studies such as Orphanides (2003) and Orphanides and Williams (2002) generate noticeably larger costs of such policy mistakes. Policy mistakes related to trend shifts lead to relatively small costs in our simulations because the monetary authority can detect these changes relatively quickly. This in turn is related to the assumptions that the monetary authority knows the correct structure of the model (except for the nature of the ERR process, of course) and uses the Kalman filter to recover the values of the shocks hitting the economy. To demonstrate this we present the results from a simulation in which the monetary authority learns about changes in the economy rather slowly, an assumption that is similar in spirit to the relatively inertial learning rule that is used by Orphanides and Williams (2002). Specifically, we alter the variance-covariance matrix of the shocks so that the it takes the monetary authority twice as long as before to detect half the cumulative shift in the trend growth rate. The results of this exercise are shown in Figure 3. Panel A of the figure shows that even with slow learning inflation does not deviate noticeably from the full information case as long as the monetary authority is assumed to know the structure of the model. Things are quite different in the simulation based upon the ex-post average real rate (Panel B of Figure 3). Now, the inflation rate exceeds inflation under the full information case by some 4 percent by the end of the simulation.

Our results demonstrate that generating a sustained change in the inflation rate in response to a change in the trend growth rate is no easy task. Ignorance about the structure of the model (here about the nature of the ERR) is not enough. As we have shown, in order to get inflation to go up after a decrease in the trend growth rate (for example), not only must the authority not know about time variation in the ERR but it must end up with an estimate of the constant ERR that is "too low." Such 
an assumption may be hard to justify when the economy is coming off a high growth - high interest rate period. And even this is not enough to generate a substantial increase in inflation out of an empirically plausible shift in the trend growth rate. For this we have also had to reduce the speed at which the monetary authority learns about the underlying shocks to the economy. Here it is worth emphasizing that this last assumption is not sufficient to generate sustained changes in inflation when the growth trend changes either; we still need to assume that the monetary authority makes the "right" kind of mistake about the ERR. ${ }^{9}$

These results also have a bearing on some recent research on robust policy rules. Specifically, Orphanides and Williams (2002) argue that "..difference rules for monetary policy, in which the short term nominal interest rate is raised in response to inflation and changes in economic activity" are likely to lead to better economic outcomes than the more conventional rules which are based on levels (such as (9) above) because they are less likely to be susceptible to mistakes in measuring natural rates (or potential growth rates). Our results suggest that because a time varying equilibrium rate can move to offset the effects of some kinds of shocks, policy rules based on levels may not always perform as badly (relative to difference rules) as would be suggested by exercises that ignore this comovement.

\subsection{Estimating policy rules}

For our second exercise we examine how the existence of a time varying equilibrium real rate affects the econometrician's ability to recover the correct coefficients when estimating policy rules. We begin by asking what happens to estimates of the policy rule when the econometrician assumes that the equilibrium real rate is constant.

We assume that the monetary authority follows the policy rule specified in equation (9). However, (for now) we assume that the econometrician believes that the policymaker sets policy according to one of the following two alternatives, either :

$$
i_{t}=\kappa^{\prime}+\hat{\pi}_{t}+\beta_{y} \widetilde{y}_{t}+\beta_{\pi}\left(\hat{\pi}_{t}-\bar{\pi}\right)
$$

\footnotetext{
${ }^{9}$ Another way to generate substantial changes in inflation is to assume a time varying inflation target, as in Kozicki and Tinsley (2001, 2003).
} 
or

$$
i_{t}=(1-\gamma)\left(\kappa^{\prime}+\hat{\pi}_{t}+\beta_{y} \widetilde{y}_{t}+\beta_{\pi}\left(\hat{\pi}_{t}-\bar{\pi}\right)\right)+\gamma i_{t-1}
$$

In equation (11) the policymaker can be viewed as adjusting gradually to a target real rate which equals a constant plus a term that depends upon the output gap and the deviation of the inflation rate from its target value. The policymaker reacts to the same set of variables in equation (10) but here the adjustment to target is assumed to be instantaneous. We now consider how the econometrician's use of one of these incorrectly specified policy rules can affect inferences about the conduct of policy.

The econometrician's assumption of a constant equilibrium rate amounts to omitting the authority's measure of the ERR in the estimated policy rule. Consider, first, what happens if the econometrician estimates a policy rule without a lagged interest rate, specifically equation (10) above. To the extent that the output and inflation variables are correlated with the authority's measure of the ERR, the estimated coefficients on these variables will be biased, with the direction and extent of the bias depending on their relationship to the equilibrium rate. ${ }^{10}$ For instance, an increase in the true ERR that was not immediately perceived by the monetary authority would tend to push up the output gap (from equation (1)) as well as inflation (equation (2)) leading to a positive correlation between the ERR and these variables. Thus, omitting the equilibrium rate would tend to bias the coefficients on these variables upwards. By contrast, a positive shock to the trend growth rate would tend to induce a negative correlation and a downward bias to the coefficient on the inflation variable in an equation such as (10). Thus, whether the estimated coefficient turns out to be larger or smaller than the true coefficient will depend upon the shocks hitting the system and the kind of correlation that they induce between different variables.

Consider now what happens if the econometrician estimates a rule that includes a lagged interest rate term, that is to say, equation (11) above. It is easy to see that the estimate of $\gamma$ will tend to be significant if there is serial correlation in $E_{t} r_{t}^{*}$ even

\footnotetext{
${ }^{10}$ For each of the variables included in the regression, the omitted variable bias equals the coefficient of the omitted variable in the correctly specified regression multiplied by the coefficient of the included variable in a regression where the omitted variable is regressed on all the included variables. See Greene(2000) for a discussion.
} 
if the monetary authority pays no attention to $i_{t-1}$, for the lagged interest rate will act as a proxy for the omitted (estimate of the) ERR. In the empirical literature the finding of a non-zero coefficient on $i_{t-1}$ is pretty much universal and is generally interpreted as evidence that the monetary authority adjusts interest rates gradually, that is, it "smooths" interest rates. Over the years, a number of theories have been proposed to motivate this behavior. ${ }^{11}$ The argument presented here is different, in as much as we argue that the coefficient on the lagged interest rate term is also affected by factors other than interest rate smoothing, and is related to arguments put forward by Rudebusch (2002) and Lansing (2002a). Rudebusch (2002) argues that monetary policy rules that allow for gradual adjustment are misspecified, and that the lagged interest rate actually reflects serially correlated shocks to the policy rule. Lansing (2002a) shows that the use of a output gap measure based on "full sample" information (that is, information that was not available to the authority at the time that policy decisions were made) when estimating policy reaction functions tends to increase the coefficient on the lagged interest rate term, thereby leading to the illusion of interest rate smoothing.

Inclusion of the proxy variable $i_{t-1}$ also alters the coefficients of the remaining variables (that is, it will cause the estimated values of $\beta_{y}$ and $\beta_{\pi}$ in (10) to be different from those in (11)), with the exact change depending upon a number of factors. The change in coefficients could be an improvement under certain conditions; for instance if $i_{t-1}$ and $E_{t} r_{t}^{*}$ were highly correlated and if the component of $i_{t-1}$ which was orthogonal to $E_{t} r_{t}^{*}$ was also orthogonal to the other variables and the error term in the estimated equation. Alternatively, if this component was large and correlated with the other variables or the error term in the estimated equation inclusion of the lagged interest rate could move the estimates of $\beta_{y}$ and $\beta_{\pi}$ further away from their true values. ${ }^{12}$

What happens when the econometrician does include a measure of the ERR in the estimated policy rule? While this is likely to make the estimated coefficients more accurate, it is unlikely to eliminate the bias entirely. As the discussion of omitted variable bias above indicates, the monetary authority generates nonzero correlations

\footnotetext{
${ }^{11}$ See, for instance, Barro(1989), Cukierman(1991), Goodfriend(1991), Woodford(1999). See also Sacks and Wieland(2000) for a more general discussion.

${ }^{12}$ See Maddala (1977) for a discussion.
} 
between the estimate of the ERR that it uses in the policy rule and either inflation or the output gap when it filters the data to determine the true state of the economy. The implication is that it will be impossible to completely eliminate this bias unless the econometrician were to come up with the exact measure of the ERR used by the monetary authority. This problem is similar to the one that arises because the econometrician does not know the value of the gap that is used by the monetary authority and that has been discussed by Lansing (2003), Orphanides (2002) and Rudebusch (2001). One reason the consequences will be different is that the econometrician is likely to impose a coefficient of 1 on the ERR, so measurement problems will show up in the other coefficients of the policy rule.

\subsubsection{Estimating a Mis-Specified Rule}

We examine these issues by undertaking sets of simulations that differ in what the policymaker and the econometrician are assumed to know about the economy. The benchmark case is one where we assume that the policymaker knows the model specification, the coefficient values as well as all the shocks hitting the system. Policy is given by (9); thus, the policymaker does not smooth interest rates. By contrast, the econometrician assumes that the ERR is constant; consequently, we assume that she uses modified versions of equations (1) and (2). Specifically, we assume that the econometrician uses versions of these equations which do not contain $r_{t}^{*}$, but whose coefficients are exactly the same as those shown above. In addition, the econometrician also knows equations (5) and (6). These assumptions allow us to focus upon the effects of the econometrician's mistake about the ERR.

Each simulation consists of 140 draws (to mimic quarterly data over a 35 year sample) of four zero-mean, normally-distributed shocks, whose standard deviations are obtained from the estimation of the model. Thus, at each point in time, the system is hit by a set of 4 shocks that determine the values of the variables that the policy authority can observe: $y_{t}$ and $\pi_{t}$. In our benchmark case the authority can see these shocks and so is able to compute the correct values of the output gap and the ERR for use in (9). Next period, the entire exercise is repeated. After the simulation is complete, that is, we have generated data for the entire period under study, we filter the data under some alternative assumptions and estimate the two 
alternative versions of the policy rule equations (10) and (11). We then record the estimates of $\beta_{y}, \beta_{\pi}$ and $\gamma$ obtained from this exercise. We repeat this exercise a thousand times.

The median estimates of the coefficients obtained from this exercise are shown in the top panel of Table 1, along with the intervals that contain 90 percent of the estimated values. ${ }^{13}$ Here we assume that the econometrician knows the gap used by the monetary authority when setting the interest rate, which in Case I is also the true output gap. The first column (A1) shows that the econometrician will recover the true coefficients of the reaction function when no lagged interest rate term is included in the equation, that is to say when she estimates the policy rule (10). This may appear surprising at first glance since equation (10) clearly omits a relevant variable: the equilbrium real rate of interest. It turns out, however, that in the model used here the ERR is not correlated with either the correctly measured output gap or the inflation rate, implying that the econometrician can expect to recover unbiased estimates of the coefficients $\beta_{y}$ and $\beta_{\pi}$. Things change once the lagged interest rate is included in the estimated equation, that is, when the policy rule (11) is estimated. The median estimates of $\beta_{y}$ and $\beta_{\pi}$ move away from the true values, reflecting the fact that the lagged interest rate is correlated with both inflation and the output gap. And the median estimated value of $\gamma$ (the coefficient on the lagged interest rate) turns out to be 0.32 with 90 percent of the estimated values lying between 0.12 and 0.64 .

For Case II we drop the assumption that the monetary authority knows the disturbances hitting the economy and assume instead that it too must filter the data to obtain estimates of the output gap and the ERR. We still maintain the assumption that the authority knows the true model. Panel A in the lower half of the table shows what happens when the econometrician knows the measure of the gap used by the monetary authority. Note that in contrast to Case I above, the econometrician no longer recovers the true values of $\beta_{y}$ and $\beta_{\pi}$ even when the lagged interest rate is not included in the estimated equation. This is because the monetary authority's

\footnotetext{
${ }^{13}$ We ignore the existence of the zero bound in the simulations presented here. Imposing the zero bound increases the size of the 90 percent intervals because of a relatively small number of simulations where the interest rate hits the zero bound. It also leads to larger coefficients on the lagged interest rate term.
} 
filtering of the data induces positive correlations between its estimates of $y_{t}$ and $r_{t}^{*}$ as well as $\pi_{t}$ and its estimate of $r_{t}^{*}$. Thus, the omission of the policymaker's measure of the ERR leads to an upward bias in the estimated coefficients of inflation and the output gap. And inclusion of the lagged interest rate actually makes things worse, as the next column indicates. While the estimate of $\beta_{\pi}$ goes up only slightly, the median value of $\beta_{y}$ rises to 0.7 and 90 percent of the time the econometrician recovers a value of $\beta_{y}$ that is larger than the true value. The median estimate of $\gamma$ turns out to be 0.24 .

Panel B (Case II) shows what happens to the estimated policy rule coefficients when the econometrician no longer has access to the measure of the output gap used by the monetary authority. The largest change is the drop in the value of $\beta_{y}$, a drop which is consistent with the results reported by Lansing(2002a), among others. Note that the decline actually moves the estimated value of $\beta_{y}$ closer to the true value than it was before. By contrast, the estimate of $\beta_{\pi}$ gets pushed a little further away from the true value. In fact, each of the changes we consider pushes the estimated value of $\beta_{\pi}$ further away from the true value. For instance, making the monetary authority filter the data to obtain estimates of $y_{t}$ and $r_{t}^{*}$ when the lagged interest rate is not included in the estimated policy rule raises the estimate of $\beta_{\pi}$ from 0.5 to 0.61 (compare the estimates of $\beta_{\pi}$ in Case I Panel A1 with those in Case II Panel A1), adding the lagged interest rate term pushes the estimate up to 0.62 (compare the estimates of $\beta_{\pi}$ in columns A1 and A2 in Case II) and dropping the assumption that the econometrician has access to the monetary authority's measure of the output gap raises the coefficient to 0.67 (Compare the estimates of $\beta_{\pi}$ in columns A2 and B2 in Case II).

Column B2 also shows that the median estimate of $\gamma$ is 0.26 percent; it turns out that the estimate of $\gamma$ is significant at the 1 percent level in 93.9 percent of the simulations. Finally, to provide a better sense of the distribution of our estimated coefficients in Case IIB we plot the frequency distributions in figure 4 (panels $\mathrm{A}$ through $\mathrm{C}$ ). The distributions of $\beta_{y}$ and $\gamma$ are noticeably skewed to the right.

For our final exercise we drop the assumption that the monetary authority is aware of the existence of $r_{t}^{*}$. This allows us to generate a set of results that are comparable to earlier results in the literature-where the policymaker is assumed to 
target a constant ERR. In this case, both the policymaker and the econometrician filter the data using the correct version of the Philips curve (that is, equation (2)), and the mis-specified version of (1), one that assumes that the ERR is a constant. Another consequence is that policy is set according to

$$
i_{t}=\kappa^{\prime \prime}+\alpha \widehat{y_{t}^{r}}+\beta\left(\hat{\pi}_{t}-\bar{\pi}\right)
$$

where $\widehat{y_{t}^{r}}$ denotes the one-sided real-time estimate of the output gap. Not surprisingly, panel A of Case III in Table 1 shows that if the econometrician also knows the value of the gap used by the monetary authority, she will recover the exact coefficients used by the monetary authority every time. If the gap must be estimated (panel B), the median value of $\beta_{y}$ drops noticeably, with the estimated value lying below the true value in more than 90 percent of the simulations, whether or not a lagged interest rate term is included in the equation. If a lagged interest rate term is included (column B2) it tends to have a small positive coefficient, which turns out to be significant at the 5 percent level in $56.9 \%$ of the simulations.

How sensitive are the results in Table 1 to the assumption that the monetary authority does not smooth interest rates? To answer this question, we repeated the entire set of exercises above under the assumption that the true policy reaction function is given by

$$
i_{t}=0.3 i_{t-1}+0.7\left(\kappa_{1}+0.5 \widetilde{y}_{t}+0.5 \hat{\pi}_{t}\right)
$$

i.e., the true value of $\gamma=0.3$. The results are shown in Table 2 and turn out to be not that different from those in Table 1. For instance, if the monetary authority targets a time varying ERR the estimated coefficient on the lagged interest rate is biased upward, with the estimated value exceeding the true value in more than 90 percent of the simulations as long as the authority knows the true model.

Implications and Empirical Significance We have shown that the coefficients that the econometrician recovers are quite sensitive to the what the monetary authority is assumed to know about the structure of the economy. Median values of $\beta_{y}$ in Table 1, for instance, range between 0.33 and 0.7 , with the true value of 0.5 lying outside the 90 percent range associated with either of these two estimates. 
The results under the perfect information assumption are clearly unrealistic and are included only to highlight the role that filtering of the data has upon the estimated coefficients. As can be seen in either Table 1 or 2 , the monetary authority's filtering of the data tends to bias upwards the estimates of $\beta_{y}$ and $\beta_{\pi}$. The upward bias in the former disappears when we make the more realistic assumption that the authority's measure of the gap is unavailable to the econometrician, which is to say that the upward bias in $\beta_{y}$ that is due to filtering is more or less offset by the downward bias induced by the use of the wrong measure of the output gap. Also the upward bias in $\gamma$, the coefficient on the lagged interest rate, is approximately 0.2 , with the exact value depending upon the assumption one makes about whether or not the authority actually smooths interest rates.

The results in Case III (in Table 1 or 2) highlight the fact that these issues only arise in a setup where the monetary authority is targeting a time varying ERR If the authority ignores this time variation we recover a more familiar set of results (as in Lansing (2002a)). Specifically, there is no upward bias in the estimate of $\beta_{\pi}$, but the econometrician's inability to obtain the appropriate measure of the output gap leads to a noticeable downward bias in the estimate of $\beta_{y}$ and a rather small upward bias in $\gamma$.

How reasonable is it to assume that the monetary authority targets a time varying ERR? The earliest explicit discussion of this issue that we have come across is in Chairman Greenspan's July 1993 testimony to Congress, where he stated that:

"One important guidepost is real interest rates, which have a key bearing on longer run spending decisions and inflation prospects.

In assessing real rates, the central issue is their relationship to an equilibrium interest rate, specifically, the level that, if maintained, would keep the economy at its production potential over time. Rates persisting above that level, history tells us, tend to be associated with slack, disinflation, and economic stagnation-below that level with eventual resource bottlenecks and rising inflation, which ultimately engenders economic contraction. Maintaining the real rate around its equilibrium level should have a stabilizing effect on the economy, directing production towards its long-term potential.

The level of the equilibrium real rate - or more appropriately the equilibrium 
term structure of real rates - cannot be estimated with a great deal of confidence, though with enough to be useful for monetary policy... Moreover, the equilibrium rate structure responds to the ebb and flow of underlying forces. So, for example, in recent years the appropriate real rate structure has doubtless been repressed by the headwinds of balance sheet restructuring and fiscal retrenchment."

It seems to us that this is not the first time that the Fed realized that equilibrium interest rates vary over time. Thus, we are inclined to interpret earlier warnings by Fed Chairmen about the need to reduce federal budget deficits as expressing a concern about the tendency of continued deficits to push up equilibrium interest rates. Empirically, then, we would argue that the results in Case IIB provide a more realistic measure of the bias in various coefficients of estimated Taylor rules-at least over the last two decades or so.

To the extent that this is true, the results of our exercise suggest that estimated policy reaction functions that do not allow for a time varying ERR are likely to have estimates of $\beta_{\pi}$ that are biased upwards. Any downward bias in $\beta_{y}$ is not likely to be very big, as the effects of not knowing the measure of the output gap used by the monetary authority are likely to be offset by the effects of not knowing the authority's measure of the ERR. As for the debate on interest rate smoothing, our estimates suggest a bias of roughly 0.2 , with relatively little of this reflecting the effects of not knowing the authority's measure of the output gap. A bias of 0.2 may not appear to be large, especially in view of the fact that $\gamma$ is often estimated to be around 0.8 or 0.9 for postwar U.S. data. However, this difference is large enough to make a noticeable difference to the implied persistence of the funds rate. For instance, if $\gamma=0.9$ it takes the monetary authority seven quarters to close half the gap between the actual and desired funds rate, while if $\gamma=0.7$ the authority takes only two quarters to cover roughly the same distance.

\subsubsection{Two Alternative Solutions}

Finally, we ask what the econometrician can do to recover more accurate values of the Taylor rule coefficients in a world where the ERR varies over time. If we assume that she knows the true structure of the model and the correct policy rule the answer is straightforward: She simply constructs an estimate of the ERR and includes it in the 
estimated policy rule. With the coefficient on the ERR restricted to 1, Table 3 shows the coefficient estimates for the remaining variables in the policy rule under different assumptions about how much the policymaker knows. In the interests of brevity we only present the results for the cases where the policymaker does not know the shocks hitting the economy and where the econometrician does not know the policymaker's measure of the output gap. Because we set $\gamma=0$ in our simulations, the two cases in Table 3 are comparable to Table 1. Including the econometrician's measure of the ERR leads to an improvements in the estimates of $\gamma$ while the estimates of $\beta_{y}$ are generally worse. The estimates of $\beta_{\pi}$ improve when the authority is assumed to know the correct model.

The assumption that the econometrician has the right model of the economy or even the one that is being used by the monetary authority and can use that to construct an ex post measure of the ERR is obviously one that is unlikely to be fulfilled in practice. In fact, any estimate of the ERR is likely to be controversial: real interest rates themselves are unobservable and equilibrium values harder to measure still. ${ }^{14}$ Consequently, we also present the results from a technique that does not require knowledge of the ERR. Specifically, this requires following the suggestion by English, Nelson and Sacks (2003) to estimate an interest rate equation that allows for both a lagged interest rate term on the right hand side and autoregressive errors. To see why this technique might work, note that they recommend estimating the following equation:

$$
i_{t}=(1-\gamma) \widehat{i_{t}}+\gamma R_{t-1}+v_{t}
$$

where

$$
\widehat{i_{t}}=a_{0}+a_{\pi} \hat{\pi}_{t}+a_{y} y_{t}
$$

and

$$
v_{t}=\rho v_{t-1}+\epsilon_{t}
$$

A look at (13) shows that estimating this equation is similar to estimating a Taylor rule with a lagged interest rate and a time varying ERR which is approximated by the $v_{t}$ term.

\footnotetext{
${ }^{14}$ For a discussion of the difficulties in estimating equilibrium real rates, see Orphanides and Williams (2002) as well as Clark and Kozicki (2004).
} 
In Table 4 we show the estimates we obtain when this specification is estimated using the same data as in Table 1 (where it was assumed that the monetary authority was not smoothing interest rates). For Case II(B) we obtain a median estimate of $\gamma$ that is quite close to zero and is noticeably smaller than the comparable estimate in Table $1^{15}$. The estimate of $\beta_{y}$ is quite close to the true value of 0.5 while $\beta_{\pi}$ is somewhat larger. In addition, the estimated value of $\rho$ is close to one; this appears to reflect a unit root in the ERR. Here it is worth emphasizing that the econometrician recovers reasonable estimates of $\beta_{y}, \beta_{\pi}$ and $\gamma$ even though she does not know the value of the output gap used by the monetary authority or even the data generating process for the ERR. In Case III(B) we obtain a slightly larger value of $\gamma$ and median estimates of $\beta_{y}$ and $\beta_{\pi}$ that are somewhat further away from the true values than we did in Case II(B). Note, however, that the estimated median value of $\rho$ is much smaller. The fact that the estimated value of $\rho$ is close to 1 when the monetary authority is assumed to target a time varying equilibrium rate but is relatively close to 0 when it is assumed to be targeting a constant ERR is consistent with our interpretation that the $\operatorname{AR}(1)$ specification is proxying for the $\mathrm{ERR}^{16}$.

While both methods are successful in eliminating the upward bias in the estimated coefficient on the lagged interest rate term (and not so successful in eliminating the upward bias in the inflation coefficient), the fact that it is hard to be certain about the equilibrium real interest rate (in part, perhaps, because of uncertainty about the underlying model of the economy) suggests that it would be better to allow for a serially correlated error term in the estimated Taylor rule. An additional advantage of this approach is that it also helps compensate for some other specification problems, such as not knowing the value of the output gap used by the monetary authority (which also tends to induce serial correlation in the error term).

\footnotetext{
${ }^{15}$ In table 4 we again restrict ourselves to the case where the econometrician does not know the value of the output gap used by the monetary authority. The alternative simulations are labelled so as to facilitate comparison across tables.

${ }^{16}$ The estimate of $\rho$ does not go to zero in the last case because the econometrician's use of the "incorrect" measure of the gap induces serial correlation.
} 


\section{Conclusions}

In this paper we have shown that ignoring time variation in the equilibrium real interest rate can affect inferences about policy in two different areas. First, we point out that when the equilibrium real rate responds positively to the trend growth rate (consistent both with theory and our empirical estimates), unperceived changes in the latter will be accompanied by unperceived changes in the former. Thus, while an unperceived downward shift in the growth trend is likely to lead to a monetary policy that is too easy the accompanying unperceived decrease in the equilibrium rate will lead to a policy that is too tight. To what extent these two mistakes offset each other depends upon the parameters of the model and the shocks hitting the system. In any event, this co-movement complicates the task of assessing the stance of monetary policy when there is a shift in the productivity trend, such as the 1970s or the 1990s. We have also pointed out a potential pitfall for analyses of the 1970s that are based on the assumption of a constant equilibrium interest rate. Specifically, we have shown that the common practice of taking the average expost real rate as a measure of the equilibrium rate over a period in which there is a significant decline in the trend growth rate will leave the econometrician with an interest rate that is too low in the early part of the sample and bias her towards the finding that policy was too easy over this period.

Second, if the econometrician assumes that the equilibrium real rate is constant she will tend to overestimate the extent to which the monetary authority smooths interest rates and will also end up overestimating the weight that the monetary authority places upon inflation. Either explicitly including a measure of the equilibrium real rate in the estimated policy rule or allowing for serially correlated errors in conventionally specified Taylor rules is enough to eliminate the upward bias in the estimated coefficient on the lagged interest rate term but not to eliminate the upward bias in the inflation coefficient. Given the roughly comparable performance of the two solutions, the second one seems preferable both because it imposes fewer informational requirements and because it can help alleviate other problems related to the specification of the estimated policy reaction function. 


\section{References}

Barro, Robert J. 1989. "Interest Rate Targeting," Journal of Monetary Economics, January, pp. 3-30.

Clark Todd and Sharon Kozicki. 2004. "Estimating Equilibrium Real Interest Rates in Real Time," mimeo, Federal Reserve bank of Kansas City.

Clarida, Richard, Jordi Gali and Mark Gertler. 1999. "The Science of Monetary Policy," The Journal of Economic Literature, December, pp.1661-1707.

Cukierman, Alex. 1991. "Why Does the Fed Smooth Interest Rates?" in Monetary Policy on the 75th Anniversary of the Federal Reserve System, Michael Belongia (Ed.). Boston: Kluwer Academic Publishers, pp. 111-143.

English, William, William Nelson and Brian Sack. 2003. "On the Significance of the Lagged Interest Rate in Estimated Monetary Policy Rules," Contributions to Macroeconomics, Vol. 3: No. 1.

Goodfriend, Marvin. 1991. "Interest Rate Smoothing in the Conduct of Monetary Policy," Carnegie Rochester Series on Public Policy Spring, pp. 7-30.

Greene, William A.(2002) Econometric Analysis, New Jersey: Prentice-Hall, Inc.

Gordon, Robert J. 1998. "Foundations of the Goldilocks Economy: Supply Shocks and the Time Varying NAIRU," Brookings Papers on Economic Activity, pp. 297333.

Greenspan, Alan. 1993. Testimony on 1993 Monetary Policy Objectives to the U.S. Senate, July 20. http://minneapolisfed.org/info/policy/mpo/mp937ag.html.

2001. "Monetary Policy Rules Based on Real Time Data," American Economic Review, September, pp. 964-985.

Kozicki, Sharon and Peter Tinsley, 2001. "Term Structure Views of Monetary Policy under Alternative Models of Agent Expectations", Journal of Economic Dynamics and Control, 25, 149-184. 
2003. "Permanent and Transitory Policy Shocks in an Empirical Macro Model with Asymmetric Information." Federal Reserve Bank of Kansas City Working Paper No 03-09.

Hamilton, James D. 1994. "Time Series Analysis," Princeton University Press, 1994.

Lansing, Kevin. 2002.(a) "Learning About a Shift in Trend Output: Implications for Monetary Policy and Inflation," Federal Reserve Bank of San Francisco Working Paper No.

2002. (b) "Real Time Estimation of Trend Output and the Illusion of Interest Rate Smoothing," Economic Review (2002), Federal Reserve Bank of San Francisco, pp. 17-34.

Laubach, Thomas and John Williams. 2003. "Measuring the Natural Rate of Interest," The Review of Economics and Statistics, November pp. 1063-1070.

Orphanides, Athanasios. 2003. "The Quest for Prosperity Without Inflation," Journal of Monetary Economics, April 2003, vol. 50, issue 3, pp. 633-63.

. 1998. "Monetary Policy Evaluation With Noisy Information," Federal Reserve Board Finance and Economics Discussion Paper Series No. 50.

Orphanides, Athanasios and John Williams. 2002. "Robust Monetary Policy Rules with Unknown Natural Rates," Brookings Papers on Economic Activity, pp. 63-146.

Rudebusch, Glenn. 2002. "Term Structure Evidence on Interest Rate Smoothing and Monetary Policy Inertia," Journal of Monetary Economics.

2001. "Is the Fed Too Timid? Monetary Policy in an Uncertain World," Review of Economics and Statistics, pp. 203-217

and Lars Svensson 1999. "Policy Rules for Inflation Targeting" in Monetary Policy Rules, edited by John Taylor, University of Chicago Press.

Sack, Brian and Volker Wieland. 2000. "Interest Rate Smoothing and Optimal Monetary Policy: A Review of Recent Empirical Evidence," Journal of Economics and Business, pp. 205-228. 
Stock, James. 1994 "Unit Roots, Structural Breaks and Trends," in R. Engle and D. Mcfadden, eds., Handbook of Econometrics, vol 4. Amsterdam: Elsevier, pp. 2739-2841.

Taylor, John. 1999. Monetary Policy Rules. Chicago: University of Chicago Press.

Woodford, Michael, 1999. "Optimal Monetary Policy Inertia," NBER Working Paper 7261 . 
Figure 1: The Simulated Evolution of Inflation Following a Permanent Reduction in the Growth Rate

Panel A: The Effect of using the Kalman Filter to Estimate a Time-Varying Real Rate (Relative to the Full-Information Case)

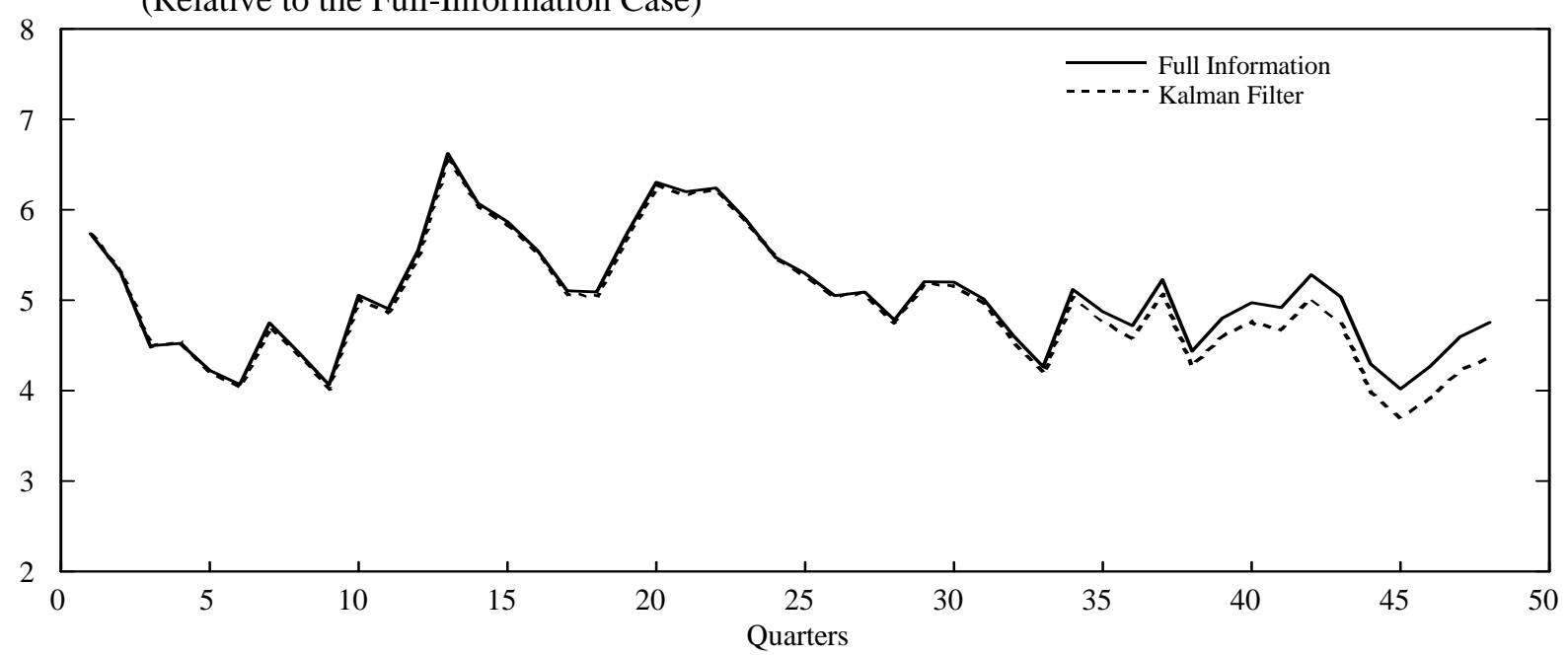

Panel B: The Effect of Using the Ex-Post Mean Real Rate

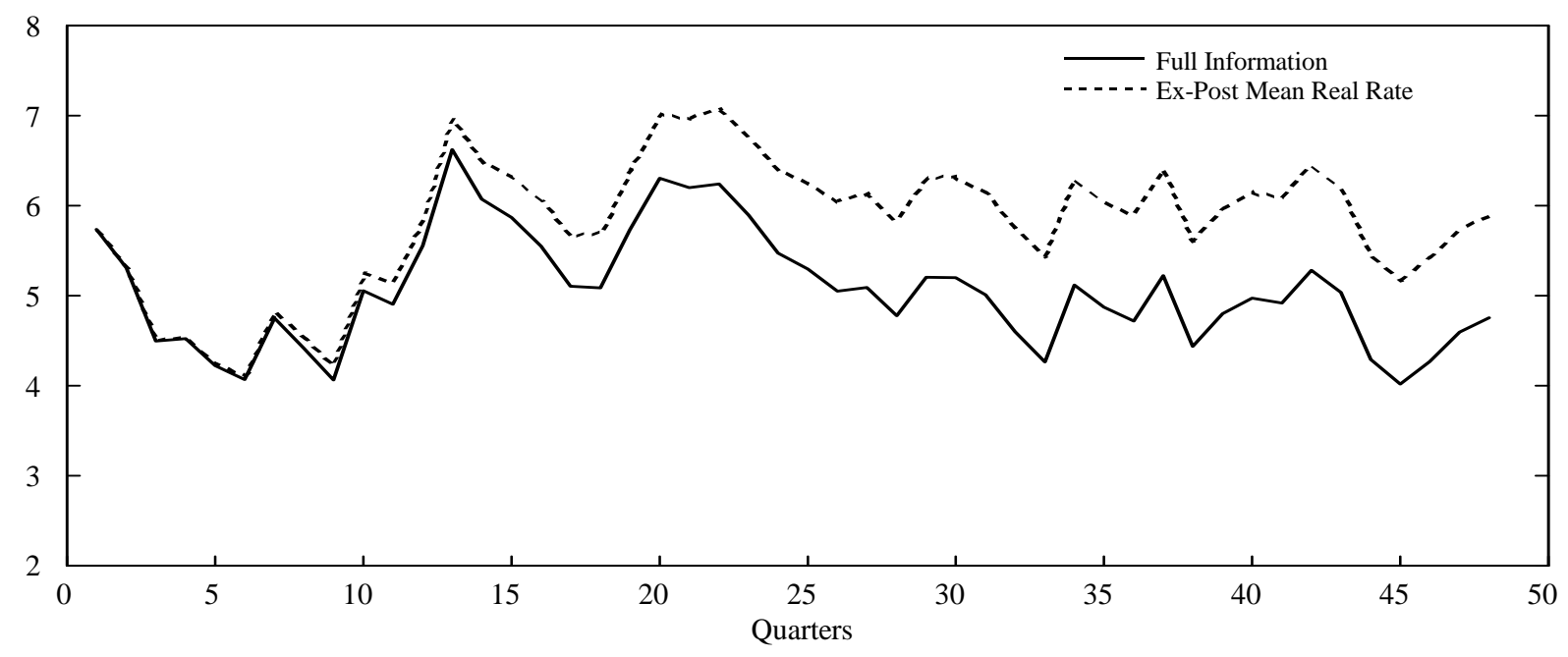

Panel C: The Effect of Using the "High-Growth" Real Rate

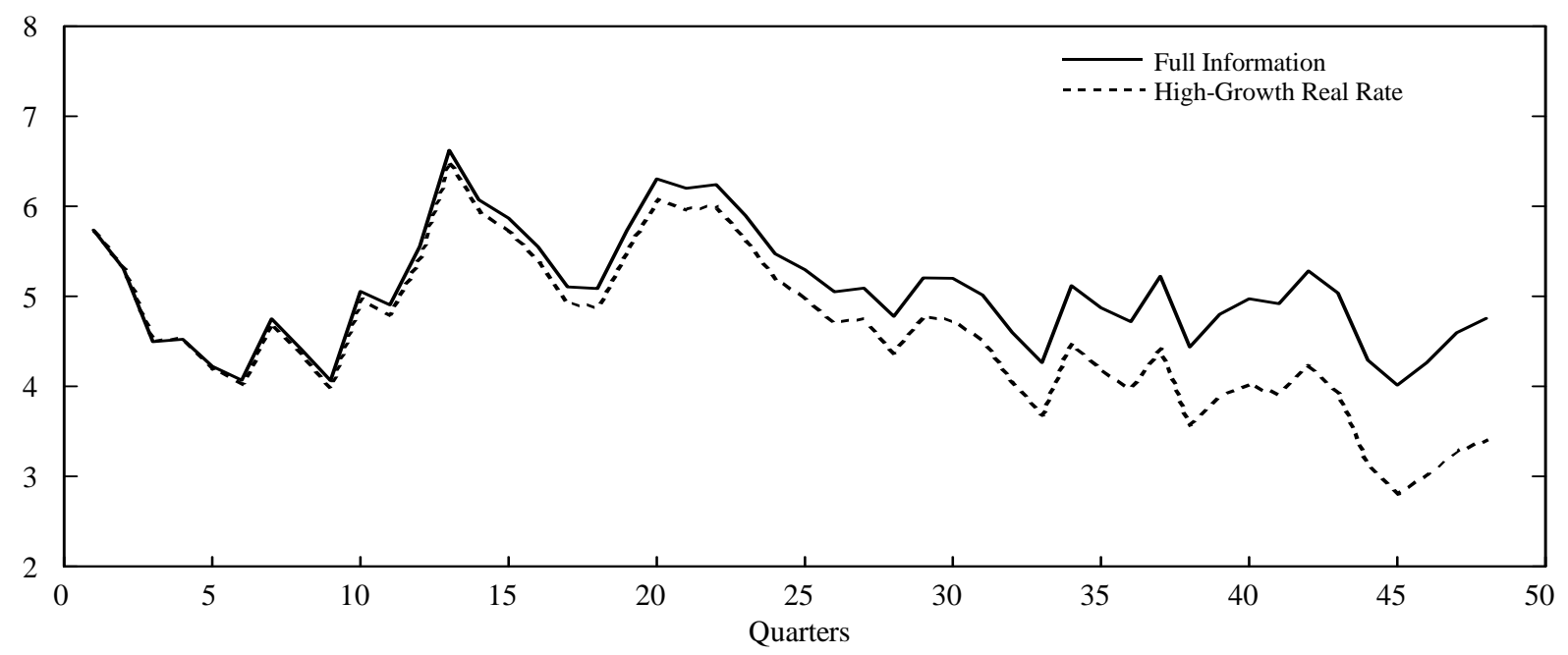


Figure 2: Equilibrium Real Rates in Different Scenarios

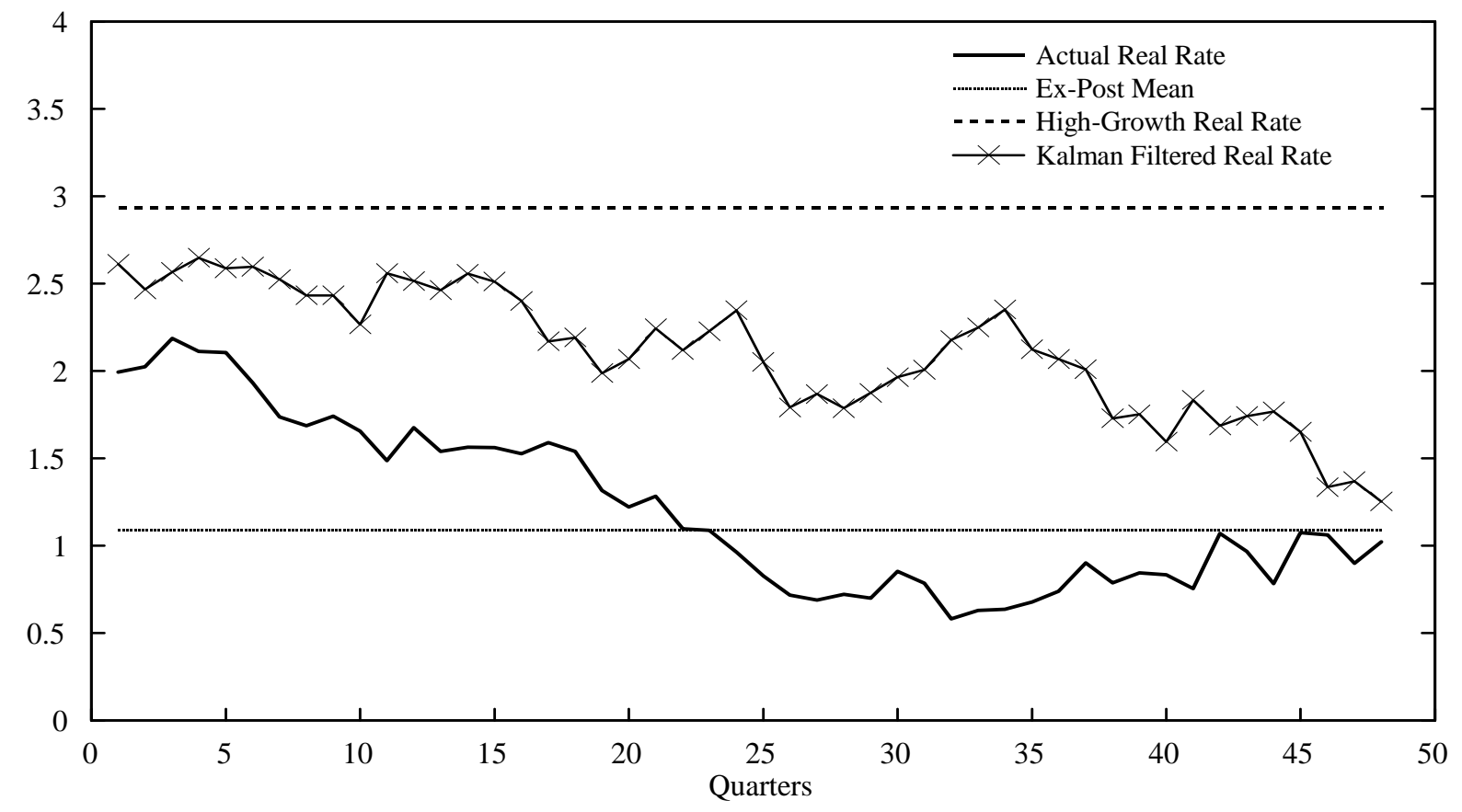


Figure 3: The Simulated Evolution of Inflation Following a Permanent Reduction in the Growth Rate - With Slow Learning

Panel A: The Effect of using the Kalman Filter to Estimate a Time-Varying Real Rate

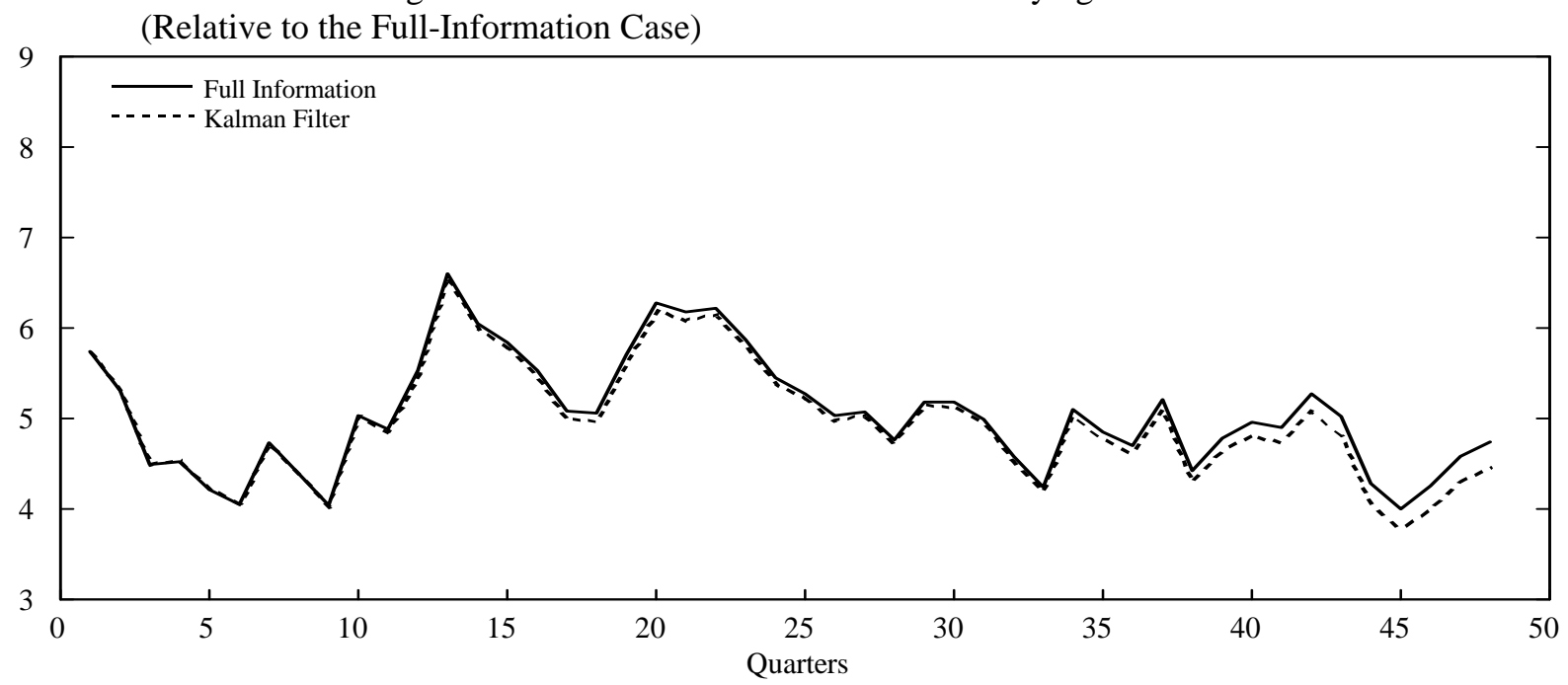

Panel B: The Effect of Using the Ex-Post Mean Real Rate

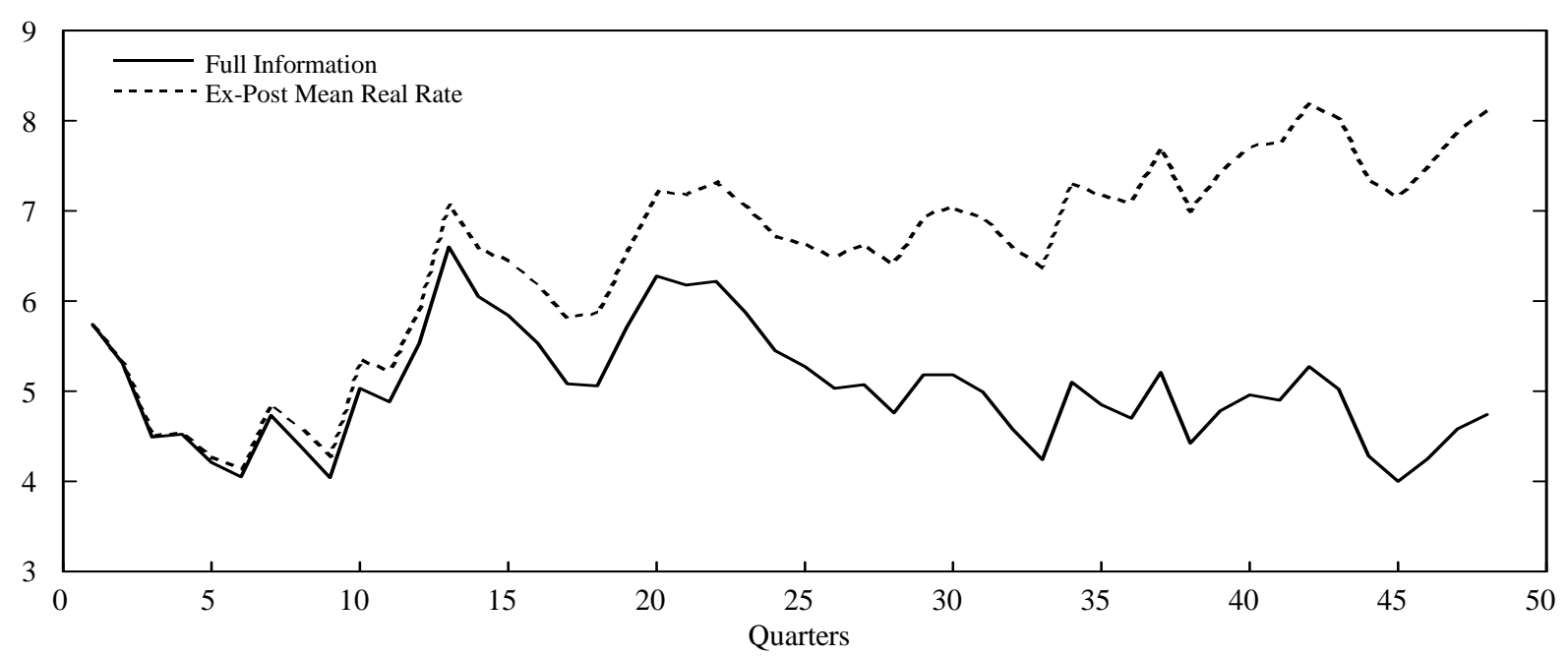


Figure 4: Empirical distributions of the estimated coefficients when the monetary authority filters the data with the true model

4 a. Distribution of $b_{\pi}\left(\right.$ true $\left.b_{\pi}=0.5\right)$

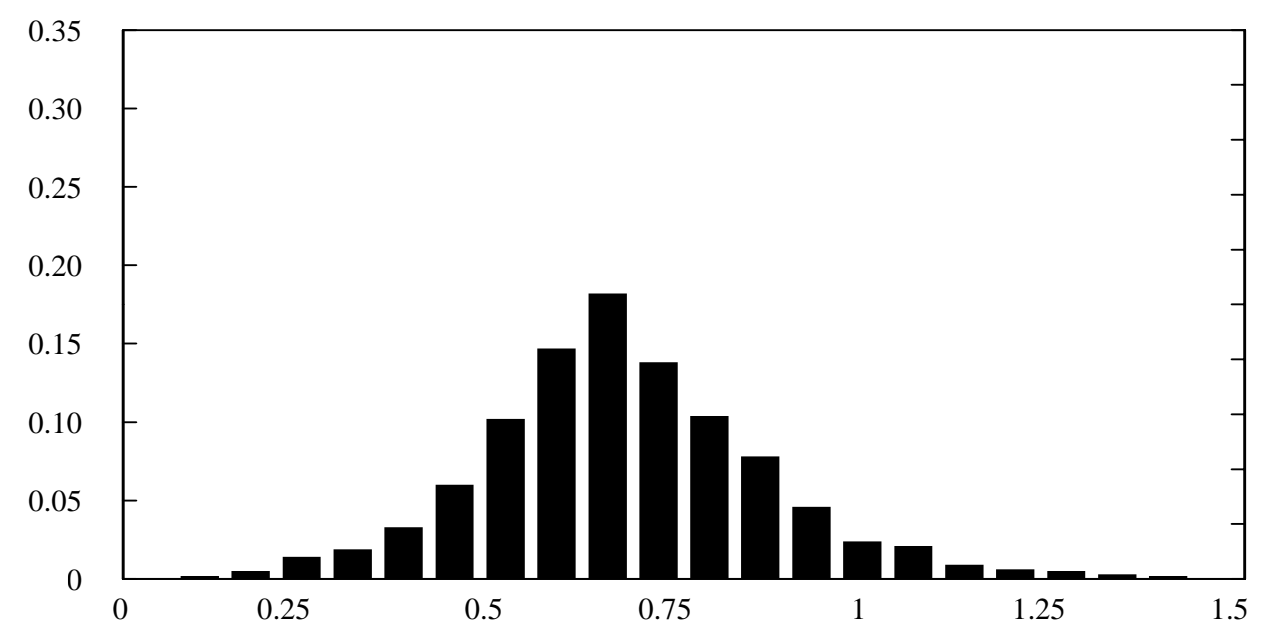

4 b. Distribution of $b_{y}\left(\right.$ true $\left.b_{y}=0.5\right)$

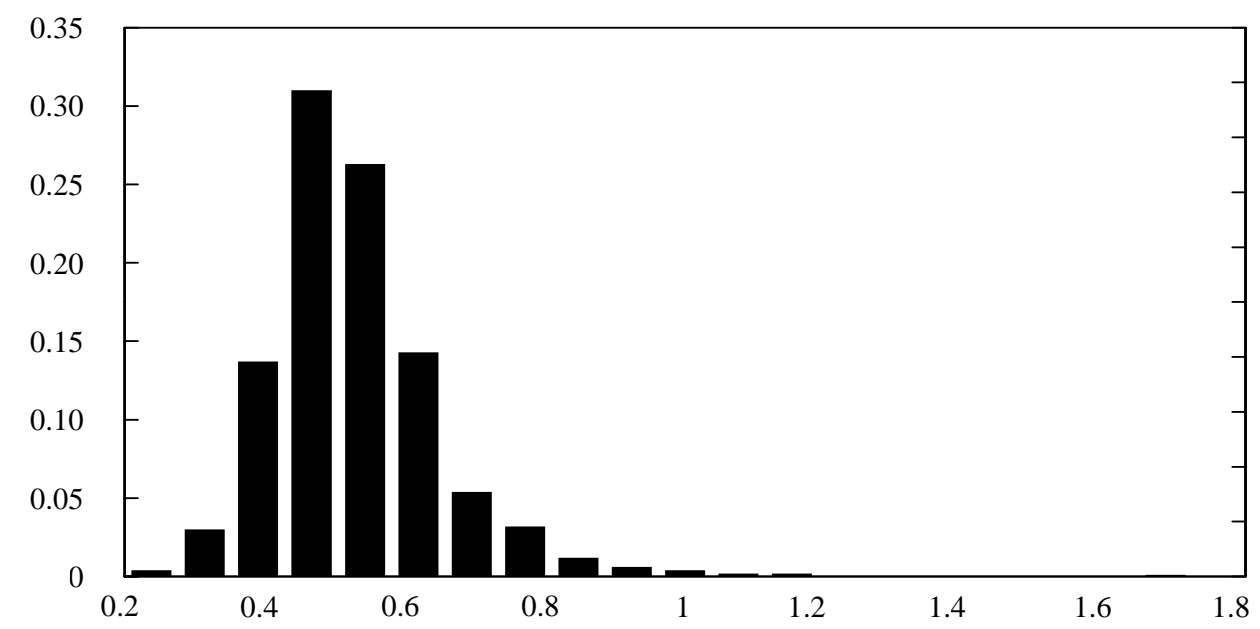

4 c. Distribution of $\gamma($ true $\gamma=0)$

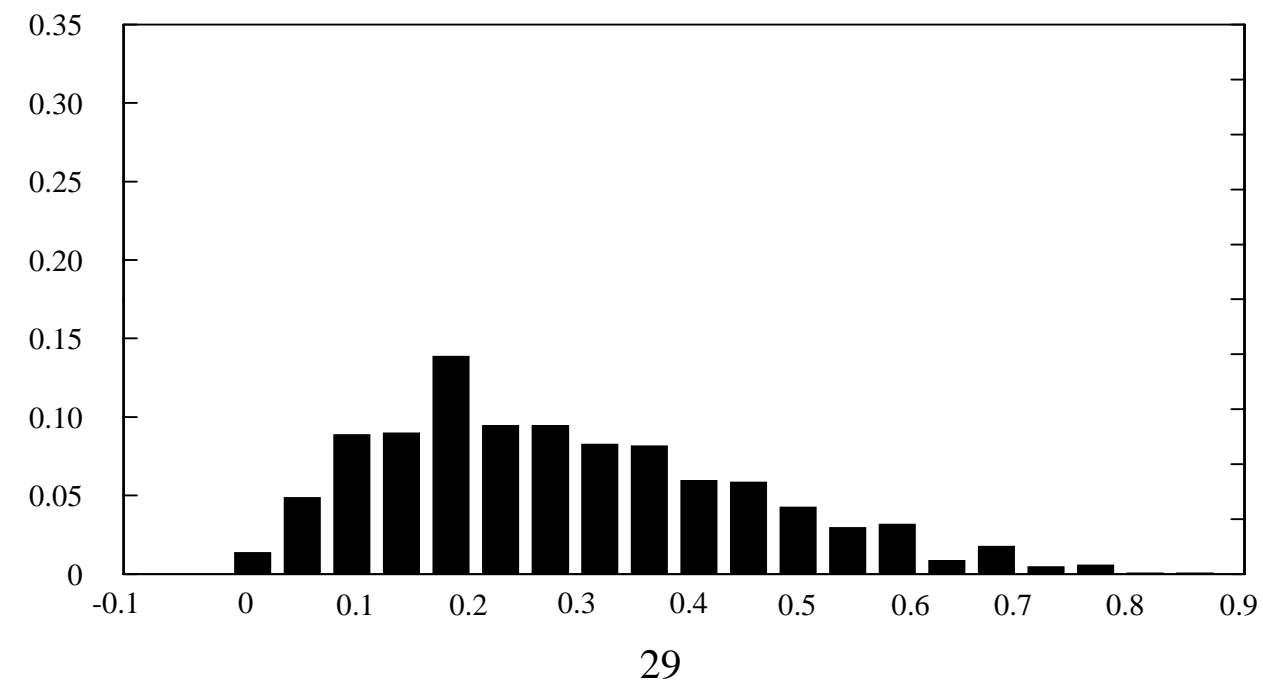


Table 1: The Effects of Ignoring $r_{t}^{*}$ when $\gamma=0$

Case I: Monetary Authority knows all

Econometrician: (A) knows authority's gap measure ${ }^{1}$

$\begin{array}{ccc} & \underline{\mathrm{A} 1} & \underline{\mathrm{A} 2} \\ \beta_{\pi} & 0.50^{2} & 0.59 \\ & (0.19,0.82) & (0.42,0.95) \\ \beta_{y} & 0.50 & 0.53 \\ & (0.32,0.68) & (0.23,0.89) \\ \gamma & & 0.32 \\ & & (0.12,0.64)\end{array}$

Case II: Monetary Authority filters with correct model

Econometrician: (A) knows authority's gap measure

$\begin{array}{ccccc} & \underline{\mathrm{A} 1} & \underline{\mathrm{A} 2} & \underline{\mathrm{B} 1} & \underline{\mathrm{B} 2} \\ \beta_{\pi} & 0.61 & 0.62 & 0.64 & 0.67 \\ & (0.37,0.86) & (0.40,0.90) & (0.34,0.93) & (0.38,1.00) \\ \beta_{y} & 0.60 & 0.70 & & 0.51 \\ & (0.41,0.74) & (0.54,0.98) & (0.25,0.58) & (0.37,0.75) \\ \gamma & & 0.24 & & 0.26 \\ & & (0.10,0.53) & & (0.06,0.60)\end{array}$

${ }^{1}$ For each panel the estimated reaction function in the second column is : $i_{t}=$ $(1-\gamma)\left(\kappa^{\prime}+\pi_{t}+\beta_{y} y_{t}^{\prime}+\beta_{\pi} \pi_{t}\right)+\gamma R_{t-1}$. In the first column $\gamma$ is set to zero. The data on which the estimates in Table 1 are based are generated by setting $\beta_{y}=0.5$, $\beta_{\pi}=0.5$ and $\gamma=0$.

${ }^{2} 90$ percent of the observations lie within the intervals shown below the reported median values 
Table 1 (Continued): The Effects of Ignoring $r_{t}^{*}$ when $\gamma=0$

Case III: Monetary Authority filters with incorrect model ${ }^{1}$

Econometrician: (A) knows authority's gap measure

$\begin{array}{ccc} & \underline{\mathrm{A} 1} & \underline{\mathrm{A} 2} \\ \beta_{\pi} & 0.50 & 0.50 \\ & (0.50,0.50) & (0.50,0.50) \\ \beta_{y} & 0.50 & 0.50 \\ & (0.50,0.50) & (0.50,0.50) \\ \gamma & & 0.00 \\ & & (0.00,0.00)\end{array}$

(B) constructs gap using incorrect model.

$\begin{array}{cc}\underline{\mathrm{B} 1} & \underline{\mathrm{B} 2} \\ 0.48 & 0.48 \\ (0.40,0.58) & (0.41,0.59) \\ & \\ 0.33 & 0.34 \\ (0.24,0.41) & (0.25,0.43) \\ & 0.07 \\ & (-0.01,0.19)\end{array}$

${ }^{1}$ See notes on previous page. 
Table 2: The Effects of Ignoring $r_{t}^{*}$ when $\gamma=0.3$

Case I: Monetary Authority knows all

Econometrician: (A) knows authority's gap measure ${ }^{1}$

$\begin{array}{ccc} & \underline{\mathrm{A} 1}^{2} & \underline{\mathrm{A} 2} \\ 0.48 & 0.54 \\ & (0.17,0.80) & (0.26,0.91) \\ \beta_{y} & 0.42 & 0.63 \\ & (0.25,0.59) & (0.45,1.06) \\ & & 0.53 \\ & & (0.38,0.75)\end{array}$

Case II: Monetary Authority filters with correct model

Econometrician: (A) knows authority's gap measure

$\begin{array}{ccccc} & \underline{\mathrm{A} 1} & \underline{\mathrm{A} 2} & \underline{\mathrm{B} 1} & \underline{\mathrm{B} 2} \\ \beta_{\pi} & 0.58 & 0.62 & 0.62 & 0.68 \\ & (0.34,0.84) & (0.41,0.92) & (0.32,0.89) & (0.40,1.03) \\ \beta_{y} & 0.47 & 0.74 & 0.35 & 0.53 \\ & (0.28,0.62) & (0.57,1.13) & (0.16,0.50) & (0.39,0.84) \\ \gamma & & & & 0.48 \\ & & 0.48 & & (0.33,0.71)\end{array}$

\footnotetext{
${ }^{1}$ For each panel the estimated reaction function in the first column is : $i_{t}=$ $(1-\gamma)\left(\kappa^{\prime}+\pi_{t}+\beta_{y} y_{t}^{\prime}+\beta_{\pi} \pi_{t}\right)+\gamma R_{t-1}$. In the second column $\gamma$ is set to zero. The data on which the estimates in Table 1 are based are generated by setting $\beta_{y}=0.5$, $\beta_{\pi}=0.5$ and $\gamma=0.3$.

${ }^{2} 90$ percent of the observations lie within the intervals shown below the reported median values.
} 
Table 2 (Continued): The Effects of Ignoring $r_{t}^{*}$ when $\gamma=0.3$

Case III: Monetary Authority filters with incorrect model ${ }^{1}$

\begin{tabular}{|c|c|c|c|c|}
\hline Econometrician: & (A) knows a & y's gap measure & (B) construc & ncorrect model. \\
\hline & $\underline{\mathrm{A} 1}$ & $\underline{\mathrm{A} 2}$ & $\underline{\mathrm{B} 1}$ & $\underline{\mathrm{B} 2}$ \\
\hline$\beta_{\pi}$ & 0.47 & 0.50 & 0.46 & 0.48 \\
\hline & $(0.45,0.49)$ & $(0.50,0.50)$ & $(0.38,0.54)$ & $(0.41,0.59)$ \\
\hline$\beta_{y}$ & 0.39 & 0.50 & 0.26 & 0.34 \\
\hline & $(0.36,0.42)$ & $(0.50,0.50)$ & $(0.18,0.34)$ & $(0.25,0.44)$ \\
\hline$\gamma$ & & 0.30 & & 0.32 \\
\hline & & $(0.30,0.30)$ & & $(0.27,0.41)$ \\
\hline
\end{tabular}

${ }^{1}$ See notes on previous page. 
Table 3: Estimating Taylor Rules with a Time Varying ERR

\begin{tabular}{ccccc} 
Policymaker: & \multicolumn{2}{c}{$\mathrm{II}(\mathrm{C})$ knows the model } & \multicolumn{2}{c}{$\mathrm{III}(\mathrm{C})$ uses } \\
\multirow{2}{*}{$\beta_{\pi}$} & 1 & 2 & 1 & 2 \\
& 0.60 & 0.61 & 0.44 & 0.44 \\
& $(0.52,0.69)$ & $(0.53,0.70)$ & $(0.23,0.66)$ & $(0.22,0.66)$ \\
$\beta_{y}$ & 0.43 & 0.44 & 0.27 & 0.27 \\
& $(0.34,0.49)$ & $(0.36,0.50)$ & $(0.09,0.39)$ & $(0.09,0.39)$ \\
$\gamma$ & & & & \\
& & 0.05 & & 0.001 \\
& & $(-0.05,0.15)$ & & $(-0.10,0.11)$
\end{tabular}

Table 4: Estimating Taylor Rules with Lagged Dependent Variables and Serially Correlated Errors ${ }^{1}$

$\begin{array}{ccc}\text { Policymaker: } & \mathrm{II}(\mathrm{B}) \text { knows the model } & \mathrm{III}(\mathrm{B}) \text { uses wrong model } \\ \beta_{\pi} & 0.58 & 0.36 \\ & (0.49,0.74) & (0.22,0.74) \\ \beta_{y} & 0.52 & 0.42 \\ & (0.44,0.60) & (0.03,0.74) \\ \gamma & -0.01 & 0.08 \\ & (-0.04,0.14) & (-0.17,0.41) \\ \rho & 0.95 & 0.15 \\ & (0.90,1.03) & (-0.02,1.01)\end{array}$

${ }^{1}$ The estimated reaction function is : $i_{t}=c+\beta_{y} y_{t}^{\prime}+\beta_{\pi} \pi_{t}+\gamma R_{t-1}+v_{t}$ where $v_{t}=\rho v_{t-1}+e_{t}$ The data on which the estimates in this Table are based are generated by setting $\beta_{y}=0.5, \beta_{\pi}=0.5$ and $\gamma=0$. 


\section{Appendix: Constructing the State-Space Rep- resentation of the Model}

Eliminating $g_{t}$ from (5) and (6) gives

$$
y_{t}^{*}=2 y_{t-1}^{*}-y_{t-2}^{*}+0.25 \varepsilon_{4 t}
$$

Therefore, the observation equations of the Kalman filter are

$$
\begin{aligned}
y_{t}-y_{t}^{*}= & a_{y 1}\left(y_{t-1}-y_{t-1}^{*}\right)+a_{y 2}\left(y_{t-2}-y_{t-2}^{*}\right)+\frac{a_{r}}{2}\left\{i_{t-1}+i_{t-2}-\left[b_{\pi 1} \pi_{t-1}\right.\right. \\
& +\frac{b_{\pi 2}}{3}\left(\pi_{t-2}+\pi_{t-3}+\pi_{t-4}\right)+\frac{b_{\pi 3}}{4}\left(\pi_{t-5}+\pi_{t-6}+\pi_{t-7}\right. \\
& \left.\left.+\pi_{t-8}\right)\right]-\left[b_{\pi 1} \pi_{t-2}+\frac{b_{\pi 2}}{3}\left(\pi_{t-3}+\pi_{t-4}+\pi_{t-5}\right)+\frac{b_{\pi 3}}{4}\right. \\
& \left.\left(\pi_{t-6}+\pi_{t-7}+\pi_{t-8}+\pi_{t-9}\right)\right]-b_{y}\left(y_{t-1}-y_{t-1}^{*}\right)-b_{y}\left(y_{t-2}-y_{t-2}^{*}\right) \\
& -b_{x 1} x_{1, t-1}-b_{x 2} x_{2, t-1}-b_{x 1} x_{1, t-2}-b_{x 2} x_{2, t-2}-\left[c\left(g_{t-1}+g_{t-2}\right)\right. \\
& \left.\left.+d\left(f_{t-1}+f_{t-2}\right)+\left(z_{t-1}+z_{t-2}\right)\right]\right\}+\varepsilon_{1 t}
\end{aligned}
$$

or,

$$
\begin{aligned}
y_{t}-y_{t}^{*}= & \left(a_{y 1}-\frac{a_{r}}{2} b_{y}\right)\left(y_{t-1}-y_{t-1}^{*}\right)+\left(a_{y 2}-\frac{a_{r}}{2} b_{y}\right)\left(y_{t-2}-y_{t-2}^{*}\right) \\
& +\frac{a_{r}}{2}\left\{i_{t-1}+i_{t-2}-\left[b_{\pi 1} \pi_{t-1}+\frac{b_{\pi 2}}{3}\left(\pi_{t-2}+\pi_{t-3}+\pi_{t-4}\right)+\frac{b_{\pi 3}}{4}\left(\pi_{t-5}+\right.\right.\right. \\
& \left.\left.\pi_{t-6}+\pi_{t-7}+\pi_{t-8}\right)\right]-\left[b_{\pi 1} \pi_{t-2}+\frac{b_{\pi 2}}{3}\left(\pi_{t-3}+\pi_{t-4}+\pi_{t-5}\right)+\frac{b_{\pi 3}}{4}\right. \\
& \left.\left(\pi_{t-6}+\pi_{t-7}+\pi_{t-8}+\pi_{t-9}\right)\right]-b_{x 1} x_{1, t-1}-b_{x 2} x_{2, t-1}-b_{x 1} x_{1, t-2}-b_{x 2} x_{2, t-2} \\
- & {\left.\left[c\left(4 y_{t-1}^{*}-4 y_{t-3}^{*}\right)+d\left(f_{t-1}+f_{t-2}\right)+\left(z_{t-1}+z_{t-2}\right)\right]\right\}+\varepsilon_{1 t} } \\
\pi_{t}= & b_{\pi 1} \pi_{t-1}+\frac{b_{\pi 2}}{3}\left(\pi_{t-2}+\pi_{t-3}+\pi_{t-4}\right)+\frac{b_{\pi 3}}{4}\left(\pi_{t-5}+\pi_{t-6}\right. \\
& \left.+\pi_{t-7}+\pi_{t-8}\right)+b_{y}\left(y_{t-1}-y_{t-1}^{*}\right)+b_{x 1} x_{1 t-1}+b_{x 2} x_{2 t-1}+\varepsilon_{2 t}
\end{aligned}
$$

Define

$$
\begin{aligned}
Y_{t} & =\left(y_{t}, \pi_{t}\right)^{\prime}, \quad S_{t}=\left(y_{t}^{*}, y_{t-1}^{*}, y_{t-2}^{*}, y_{t-3}^{*}, z_{t}, z_{t-1}, z_{t-2}\right)^{\prime} \\
X_{t} & =\left(y_{t-1}, y_{t-2}, i_{t-1}, i_{t-2}, \pi_{t-1}, \pi_{t-2}, \ldots, \pi_{t-9}, x_{1, t-1}, x_{2, t-1}, x_{1, t-2}, x_{2, t-2}, f_{t-1}, f_{t-2}\right)^{\prime}
\end{aligned}
$$


Then (14), (15) become

$$
\begin{aligned}
& Y_{t}=\left[\begin{array}{c}
y_{t} \\
\pi_{t}
\end{array}\right] \\
& =\left[\begin{array}{cccccccc}
a_{y 1}-\frac{a_{r}}{2} b_{y} & a_{y 2}-\frac{a_{r}}{2} b_{y} & \frac{a_{r}}{2} & \frac{a_{r}}{2} & -\frac{a_{r}}{2} b_{\pi 1} & -\frac{a_{r}}{2}\left(\frac{b_{\pi 2}}{3}+b_{\pi 1}\right) & -\frac{a_{r}}{3} b_{\pi 2} & -\frac{a_{r}}{3} b_{\pi 2} \\
b_{y} & 0 & 0 & 0 & b_{\pi 1} & \frac{b_{\pi 2}}{3} & \frac{b_{\pi 2}}{3} & \frac{b_{\pi 2}}{3}
\end{array}\right. \\
& \begin{array}{cccccccc}
-\frac{a_{r}}{2}\left(\frac{b_{\pi 3}}{4}+\frac{b_{\pi 2}}{3}\right) & -\frac{a_{r}}{4} b_{\pi 3} & -\frac{a_{r}}{4} b_{\pi 3} & -\frac{a_{r}}{4} b_{\pi 3} & -\frac{a_{r}}{8} b_{\pi 3} & -\frac{a_{r}}{2} b_{x 1} & -\frac{a_{r}}{2} b_{x 2} & -\frac{a_{r}}{2} b_{x 1} \\
\frac{b_{\pi 3}}{4} & \frac{b_{\pi 3}}{4} & \frac{b_{\pi 3}}{4} & \frac{b_{\pi 3}}{4} & 0 & b_{x 1} & b_{x 2} & 0
\end{array} \\
& \left.\begin{array}{ccc}
-\frac{a_{r}}{2} b_{x 2} & -\frac{a_{r}}{2} d & -\frac{a_{r}}{2} d \\
0 & 0 & 0
\end{array}\right] X_{t} \\
& +\left[\begin{array}{ccccccc}
1 & -a_{y 1}+\frac{a_{r}}{2} b_{y}-2 a_{r} c & -a_{y 2}+\frac{a_{r}}{2} b_{y} & 2 a_{r} c & 0 & -\frac{a_{r}}{2} & -\frac{a_{r}}{2} \\
0 & -b_{y} & 0 & 0 & 0 & 0 & 0
\end{array}\right] S_{t}+\left[\begin{array}{c}
\varepsilon_{1 t} \\
\varepsilon_{2 t}
\end{array}\right] \\
& =A^{\prime} X_{t}+H^{\prime} S_{t}+w_{t} \\
& {\left[\begin{array}{c}
y_{t}^{*} \\
y_{t-1}^{*} \\
y_{t-2}^{*} \\
y_{t-3}^{*} \\
z_{t} \\
z_{t-1} \\
z_{t-2}
\end{array}\right]=\left[\begin{array}{ccccccc}
2 & -1 & 0 & 0 & 0 & 0 & 0 \\
1 & 0 & 0 & 0 & 0 & 0 & 0 \\
0 & 1 & 0 & 0 & 0 & 0 & 0 \\
0 & 0 & 1 & 0 & 0 & 0 & 0 \\
0 & 0 & 0 & 0 & \rho_{1} & \rho_{2} & 1-\rho_{1}-\rho_{2} \\
0 & 0 & 0 & 0 & 1 & 0 & 0 \\
0 & 0 & 0 & 0 & 0 & 1 & 0
\end{array}\right]\left[\begin{array}{c}
y_{t-1}^{*} \\
y_{t-2}^{*} \\
y_{t-3}^{*} \\
y_{t-4}^{*} \\
z_{t-1} \\
z_{t-2} \\
z_{t-3}
\end{array}\right]+\left[\begin{array}{c}
0.25 \varepsilon_{4 t} \\
0 \\
0 \\
0 \\
\varepsilon_{3 t} \\
0 \\
0
\end{array}\right]}
\end{aligned}
$$

or,

$$
S_{t}=F S_{t-1}+v_{t}
$$

Equation (17) and (19) thus become the observation and state equations of the Kalman filter. The parameters to be estimated are

$$
\theta=\left(c, d, \rho_{1}, \rho_{2}, \sigma_{3}^{2}, \sigma_{4}^{2}, \sigma_{1}^{2}, \sigma_{2}^{2}, a_{y 1}, a_{y 1}+a_{y 2}, a_{r}, b_{y}, b_{\pi 1}, b_{\pi 2}, b_{x 1}, b_{x 2}\right)^{\prime}
$$

